\title{
Cancer Care Amidst Covid-19 Pandemic in Third Tier City of India
}

\author{
Deepak Abrol', Rahul Sharma², Pawan kumar ${ }^{3}$
}

${ }^{1}$ Department of Radiation Oncology, Government Medical College Kathua, India. ${ }^{2}$ Department of Radiotherapy, Government Medical College Jammu, India. ${ }^{3}$ Medical officer Radiation Oncologist GMC KATHUA, India.

\begin{abstract}
Covid-19 has hit the health services being provided. The worst hit are far flung areas. We provide a brief over view of cancer services being derailed due to the ongoing pandemic in third tier city of India. This article also highlights how restricted movements are leading to diagnosis of cancer in late stages and thus increasing mortality.
\end{abstract}

Keywords: COVID-19- Cancer care- India

\section{Introduction}

December month of 2019 witnessed COVID-19 triggered by severe acute respiratory syndrome corona virus-2 in Wuhan, Hubei, China and it has turned into health crises of global proportion like never before [1].

COVID pandemic has changed the way of life. Wearing masks, maintaining social distance, staying home and meetings on virtual platform are new normal. Economy, polity, social life and businesses are all hit hard as if we are progressing towards a different world altogether. Health sector is no exception with new innovations coming in place, be it indoor or outdoor care.

Amongst health sector, cancer care is worst hit. Till now no data is showing more incidence of COVID-19 or SARS-COV-2 asymptomatic infections in patients with cancer. However limited data from China and more recently Rome, Italy and US are showing a higher risk [2]. According to a study in 1590 COVID-19 cases of China, a total of $1 \%$ patient had a history of cancer which seems to be higher than the average incidence of cancer in overall Chinese population [3].

Although various kinds of guidelines have been formulated which all points toward giving priority to Cancer Patients, But providing cancer care services in third tier city of a country like India provides great challenge as here the problem is not only COVID and cancer care but lack of awareness regarding cancer adding fuel to the fire.

Working in Kathua the gateway to union territory to
$\mathrm{J} \& \mathrm{~K}$, we experienced peculiar problems in delivering cancer care services during last seven months. In a country like India with low resources and overburdened healthcare system we need to make difficult decisions in our daily practice about how and when to provide cancer treatment [4].

The oncology team at GMC Kathua divided the patients into high priority, medium priority and low priority cases. Patients include those referred to oncology OPD.

High priority - condition of patients immediately life threatening clinically unstable and the intervention will provide significant overall survival or improvement in quality of life.

Medium priority - condition non-critical but dealing the treatment potentially will impact survival.

Low priority- condition stable enough that services can be delayed during COVID-19 crises or the intervention is non priority.

We treated patients keeping in mind the above mentioned status.

The problem being faced in these types of cities is non availability of drugs during the early phase of complete lockdown. Restricted moments lead to less patients coming to hospitals for non availability of transport, fear of COVID and waiting for lockdown to get over. Delay in elective surgeries and biopsies also lead to less

Corresponding Author:

Dr. Deepak Abrol, Assistant Professor

Department of Radiation Oncology, Government Medical College Kathua, India.

Email: Crabecon@gmail.com 
number of patients coming to cancer clinics. As a result when the lockdown got over we saw a surge in stage four malignancies some of which could have been prevented had the intervention done in early stages.

Due to lack of awareness about cancer in certain far-flung areas, people took the symptoms lightly, thinking to get to hospital only when lockdown gets over resulting in presentation in late stages. Another problem peculiar to Cancer Patients Is that they are vulnerable groups needing frequent visits To Healthcare Settings and Susceptible to Infections

Case 1: Patient A, 18 year old female developed pain abdomen in January 2020. She got her ultrasound done which suggested cystic swelling in ovary. Due to lockdown she couldn't get treatment for 6 months. In the month of July she landed with huge abdominal swelling. Tumor markers like AFP, Beta HCG were elevated and ultra sound guided FNAC suggested Mix Germ cell Tumor. Patient was started on BEP and showed good response to first dose.

Case 2: Patient B, 52 year old female was operated for Gall bladder mass. In December 2019 HPE reported well differentiated Adenocarcinoma staged as $1 \mathrm{~A}$ and was advised Redo surgery with wedge resection of liver by a surgical oncologist. Due to COVID-19 pandemic she couldn't get surgery done. In month of June 2020 she presented with a fungating ulcerative swelling over epigastric region. Edge biopsy was advised which showed features of Adenocarcinoma. Patient was started on palliative chemotherapy.

Though the patient A, got diagnosed with a treatable malignancy and may think herself lucky, the patient B who could have been saved with long overall survival suffered due to COVID-19 crises. These two cases only show the tip of iceberg of the problems faced by cancer patients during Covid-19 pandemic and the list is endless. Half of cancer patients and survivors who responded to a recent survey had reported changes, delays, or disruptions to the care they were receiving. The survey with, 1219 respondents was conducted by American Cancer Society Cancer Action Network (ACS CAN) [5].

What prompted us for writing this article is that we should be prepared enough to serve patients of such non communicable diseases. At no point patient of cancer, diabetes or any other such disease should suffer because of resources being turned towards COVID-19 pandemic. Though we agree that patients of COVID-19 need utmost care but mortality rate of non communicable diseases combined is high enough to seek attention of authorities and a policy should be in place to help such patients in any future eventuality.

\section{References}

1. Mei H, Dong X, Wang Y, Tang L, Hu Y. Managing patients with cancer during the COVID-19 pandemic: frontline experience from Wuhan. The Lancet Oncology. 2020 05;21(5):634-636. https://doi.org/10.1016/s1470-2045(20)30238-2

2. ESMO Website (cancer and covid-19).

3. Liang W, Guan W, Chen R, Wang W, Li J, Xu K, Li C, Ai Q, Lu W, Liang H, Li S, He J. Cancer patients in SARSCoV-2 infection: a nationwide analysis in China. The Lancet Oncology. 2020 03;21(3):335-337. https://doi.org/10.1016/ s1470-2045(20)30096-6

4. Shriya Das Adikari, Nitin Gupta, Atul Sharma, S V S Deo, Sushma Batnagar. Caring of cancer patients during COVID-19. A real life challenge. Indian Journal of Cancer Year 2020 .57(2):218-20.

5. ROXANE NELSON, RN, BSN. Cancer patients report delays in treatment because of covid-19. Medscape Medical news, April 172020.

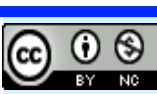

This work is licensed under a Creative Commons AttributionNon Commercial 4.0 International License. 